\title{
Desenvolvimento de Spodoptera eridania (Cramer) (Lepidoptera: Noctuidae) em diferentes hospedeiros
}

\author{
Development of Spodoptera eridania (Cramer) (Lepidoptera: Noctuidae) \\ in different hosts
}

\author{
Flávio Gonçalves de Jesus ${ }^{1 *}$, Paulo Vinicius de Sousa', Bruna Ribeiro Machado1, \\ Alexandre Igor de Azevedo Pereira', Gleina Costa Silva Alves ${ }^{2}$
}

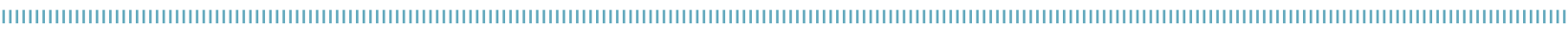

RESUMO: Spodoptera eridania (Cramer) é uma praga em expansão nas culturas, que vem causando prejuízos pela desfolha e pela lesão nas estruturas reprodutivas, o que leva à necessidade de estudos de desenvolvimento em diferentes tipos de hospedeiros. O objetivo do trabalho foi estudar o desenvolvimento de $S$. eridania em diferentes espécies de plantas hospedeiras. As lagartas foram criadas em laboratório em plantas de algodoeiro do cultivar Delta Opal. As lagartas recém-eclodidas foram individualizadas em placas de Petri e alimentadas com as plantas: mucuna-preta (Stizolobium aterrimum), feijão-guandu (Cajanus cajan), feijáo-de-porco (Canavalia ensiformes), nabo-forrageiro (Raphanus sativus), Crotalaria juncea e milheto (Pennisetum americanum). Os parâmetros avaliados foram: atratividade e consumo em teste com chance de escolha; viabilidade; período e peso larval e pupal; razão sexual; longevidade de adultos; e duração total do ciclo de desenvolvimento. As plantas de feijáo-de-porco e nabo-forrageiro apresentaram maior atratividade e foram as mais consumidas pelas lagartas de S. eridania. O período larval foi menor nas lagartas alimentadas com mucuna-preta do que com feijão-guandu, feijāo-de-porco, nabo-forrageiro e $C$. juncea. Lagartas alimentadas com folhas de nabo-forrageiro e $C$. juncea tiveram os maiores peso de pupa. Os melhores desenvolvimentos das lagartas foram obtidos nos hospedeiros feijão-guandu, nabo-forrageiro e $C$. juncea. O hospedeiro milheto influenciou negativamente os parâmetros biológicos das lagartas, provando não ser um hospedeiro viável, visto que a mortalidade larval foi de $100 \%$.

PALAVRAS-CHAVE: lagarta preta; ecologia nutricional; hospedeiro alternativo.

\begin{abstract}
Spodoptera eridania (Cramer) is a growing pest in crops that has been causing damage due to defoliation and lesion in reproductive structures, which requires studies of development in different types of hosts. The objective of this study was to evaluate the development of $S$. eridania in different species of host plants. The larvae were reared in laboratory in cotton plants of the Delta Opal cultivar. The caterpillars of newly hatched larvae were placed in Petri dishes and fed on these plants: black velvet bean (Stizolobium aterrimum), guandu bean (Cajanus cajan), jack bean (Canavalia ensiformes), forage radish (Raphanus sativus), sunnhep (Crotalaria juncea) and millet (Pennisetum americanum). The following parameters were evaluated: attractiveness and consumption in a multiple choice test; viability; larval and pupal period and weight; sex ratio; adult longevity; and total duration of the development cycle. The jack bean and forage radish plants showed greater attractiveness and were the most consumed ones by $S$. eridania caterpillars. The larval period was shorter among the larvae fed on black velvet beans in comparison to guandu beans, jack beans, forage radish and C. juncea. Larvae fed on forage radish and C. juncea leaves had the heaviest pupal weight. The best progress of caterpillars was obtained in the following hosts: guandu bean, forage radish and $C$. juncea. The millet had a negative influence on the biological parameters of caterpillars, thus not proving to be a viable host, since larval mortality was of $100 \%$.
\end{abstract}

KEYWORDS: black caterpillar; nutritional ecology; alternative host.

'Instituto Federal Goiano (IF Goiano) - Urutaí (GO), Brasil.

2Universidade Federal de Goiás (UFG) - Nova Veneza (GO), Brasil.

*Autor correspondente: fgjagronomia@zipmail.com.br

Recebido em: 13/06/2012. Aceito em: 23/10/2013 


\section{INTRODUÇÃO}

Recentemente, lagartas do complexo Spodoptera spp. têm sido relatadas como pragas de importância em regióes agrícolas do cerrado brasileiro, ocasionando danos a diversas culturas (Fernandez, 2002; SouZA et al., 2013). As lagartas cortam as plantas jovens na base do caule, causam desfolhamento e perfuram as estruturas reprodutivas (botôes florais, flores, maçãs e vagens), podendo ser consideradas como a principal praga com grande potencial de dano para as culturas do algodoeiro, Gossypium hirsutum (SANTos et al., 2010); soja, Glycine max (Sosa-Gómez, 1993; Souza et al., 2012); milho, Zea mays (Pitre; Hogg, 1983); tomate, Lycopersicum esculento (Pereira et al., 2009); e feijāo, Phaseolus vulgaris (SAvoie, 1988).

A espécie $S$. eridania, que tradicionalmente não era relevante, está sendo considerada como praga nas principais culturas das regiôes de cultivo no cerrado. Nessa região, as lagartas migram das plantas de soja em final de ciclo e passam para plantas daninhas, como a corda-de-viola (Ipomoea grandifolia), permanecendo neste hospedeiro. Posteriormente, migram para outras culturas, ocasionando os danos (SANTOS et al., 2005).

Diversas plantas daninhas são utilizadas por insetos como hospedeiros secundários, de manutenção temporária, na ausência de hospedeiros principais. No final do ciclo das culturas, muitas pragas abandonam os campos cultivados e dirigem-se aos abrigos constituídos por plantas silvestres, utilizando-as como refúgio e local de alimentação. Alguns estudos referentes aos aspectos biológicos da praga foram realizados com diferentes hospedeiros, demonstrando que esta espécie se desenvolve tanto em culturas comerciais como em plantas daninhas (SANTos et al., 2005; Dias et al., 2009).

Outras análises referentes aos aspectos biológicos da praga foram realizadas com diferentes espécies de hospedeiros, demonstrando que esse gênero está adaptado a diferentes espécies vegetais. A fase larval da S. eridania é mais longa na soja em comparação ao algodáo e à corda-de-viola, proporcionando sobrevivência superior a $80 \%$, cujo número de instares variou de seis a sete. Pupas oriundas de lagartas criadas em algodáo apresentam menor desenvolvimento em relação às provenientes de corda-de-viola. Insetos machos submetidos à dieta com folhas de soja viveram em média 3,2 e 1,9 dias a menos, quando comparados aos alimentados com folhas de algodoeiro e corda-de-viola (SANTOS et al., 2005).

De acordo com Panizzi; Parra (2009), o conhecimento da biologia de um inseto é de fundamental importância para desenvolver estratégias eficientes dentro dos conceitos do manejo integrado de pragas.

Assim, visando conhecer a importância desses hospedeiros no desenvolvimento da espécie, objetivou-se avaliar a biologia e o comportamento de S. eridania em folhas de mucuna-preta, feijāo-guandu, feijāo-de-porco, nabo-forrageiro, Crotalaria juncea e milheto.

\section{MATERIAL E MÉTODOS}

O trabalho foi conduzido no Laboratório de Entomologia Agrícola do Instituto Federal Goiano, campus Urutaí (GO), em temperatura ambiente. A biologia do inseto foi avaliada em seis hospedeiros: mucuna-preta (Stizolobium aterrimum), feijāo-guandu (Cajanus cajan), feijão-de-porco (Canavalia ensiformes), nabo-forrageiro (Raphanus sativus), Crotalaria juncea e milheto (Pennisetum americanum). Os parâmetros biológicos avaliados foram: atratividade e consumo em teste com chance de escolha; viabilidade; duração do período larval e pupal; peso larval e pupal; razão sexual; longevidade de adultos; e duração total do ciclo de desenvolvimento.

\section{Criação de Spodoptera eridania}

Massas de ovos foram coletadas em plantas de algodoeiro na fazenda do próprio campus, sendo mantidas no laboratório em condiçóes ambientes. Utilizaram-se gaiolas de PVC com $21,5 \mathrm{~cm}$ de altura e $14,5 \mathrm{~cm}$ de diâmetro, contendo em seu interior um recipiente de vidro de $150 \mathrm{~mL}$ com água. Neste local, o broto apical do cultivar de algodoeiro Delta Opal foi acondicionado para a manutenção da criaçáo, e estes brotos foram trocados a cada dois dias. Os adultos emergidos foram alimentados através de chumaço de algodáo embebido com solução de mel a $10 \%$, dispostos em tampas plásticas de refrigerante tipo PET no interior das gaiolas.

Cada gaiola recebeu cinco casais de S. eridania para efetuarem posturas. Após a eclosão das lagartas, estas foram mantidas em números de 20 insetos por recipiente, trocando-se o alimento a cada dois dias até a fase de pupa. Após a sexagem, as pupas foram transferidas para placas de Petri ( 9 x $1,5 \mathrm{~cm}$ ) até a emergência de adultos.

\section{Teste de atratividade e alimentação de Spodoptera eridania nos hospedeiros}

$\mathrm{O}$ teste de atratividade com chance de escolha foi realizado em laboratório, oferecendo discos de folhas dos seis hospedeiros para larvas de $1^{\circ}$ ínstar. As folhas foram coletadas no campo, na parte apical da planta, e cortadas em discos de $2,5 \mathrm{~cm}$ de diâmetro, distribuídos de forma circular em uma placa de Petri de $14 \mathrm{~cm}$ de diâmetro sobre papel filtro umedecido.

Das folhas coletadas de cada hospedeiro foram retirados dois discos foliares equidistantes, sendo um oferecido para o inseto, e outro, denominado alíquota, levado para secar em estufa a $60^{\circ} \mathrm{C}$ durante 48 horas. Posteriormente, pela diferença entre esta alíquota e a sobra do disco consumido determinou-se a massa seca consumida pelo inseto.

A atratividade foi avaliada pela contagem aos 5, 15, $30 \mathrm{e}$ 60 minutos e 2, 6, 12 e 24 horas após a liberação das lagartas, 
contando-se o número de insetos atraídos nos discos foliares de hospedeiros nos respectivos tempos. Duas lagartas foram liberadas para cada hospedeiro, admitindo-se dez repetiçóes em delineamento de blocos casualizados.

\section{Biologia de Spodoptera eridania nos hospedeiros}

Foram utilizadas 50 lagartas recém-eclodidas, provenientes da criação de manutenção, as quais foram transferidas para placas de Petri de $6 \mathrm{~cm}$ de diâmetro, contendo uma folha ou parte de uma folha do hospedeiro e um pedaço de algodáo hidrófilo umedecido. Antes de serem fornecidas, as folhas foram tratadas com soluçấo de hipoclorito de sódio $(0,5 \%)$ durante um minuto, sendo em seguida mergulhadas em água destilada pelo mesmo período e postas a secar à sombra por uma hora, visando eliminar entomopatógenos que pudessem contaminar as lagartas. Da mesma maneira, as folhas de cada hospedeiro foram trocadas a cada dois dias. Ao atingirem o estádio de pupa, estas foram transferidas para copos plásticos de 7,3 cm de diâmetro x $5,3 \mathrm{~cm}$ de altura, onde permaneceram até a emergência dos adultos. A pesagem das lagartas foi feita com 15 dias de idade, e das pupas, 24 horas após a pupação, quando também foi feita a sexagem, de acordo com Butt; Cantu (1962). A razão sexual foi calculada através da fórmula $\mathrm{RS}=\mathrm{n}^{\circ}$ de fêmeas $/$ $\mathrm{n}^{\circ}$ fêmeas $+\mathrm{n}^{\circ}$ machos (GAllo et al., 2002).
Para avaliaçáo da longevidade, os adultos emergidos foram individualizados em gaiolas de PVC $(10 \mathrm{~cm}$ de diâmetro x $20 \mathrm{~cm}$ de altura), fechadas na extremidade superior com filó e na inferior com placa de Petri. Os adultos foram alimentados com solução aquosa de mel a $10 \%$, colocada em um recipiente de plástico embebido em algodáo. $\mathrm{O}$ alimento foi renovado diariamente, evitando a contaminação e a fermentação por micro-organismos.

\section{Análise estatística}

Os dados foram submetidos à análise de variância pelo teste F, e as médias foram comparadas pelo teste de Tukey a $5 \%$ de probabilidade, sendo as informaçóes dos parâmetros biológicos transformadas em raiz quadrada de $(x+0,5)$.

\section{RESULTADOS E DISCUSSÃO}

Os valores referentes à atratividade de lagartas de $1^{\circ}$ ínstar de S. eridania aos hospedeiros em teste com chance de escolha diferiram entre si, em todos os tempos avaliados (Tabela 1). A espécie feijão-de-porco foi a mais atrativa em todas as avaliaçôes realizadas. De maneira geral, ao longo dos tempos analisados, as espécies milheto e $C$. juncea foram as menos atrativas à praga.

Tabela 1. Número médio ( \pm EPM) de lagartas de $3^{\circ}$ ínstar de Spodoptera eridania em discos foliares de diferentes hospedeiros, em teste com chance de escolha.

\begin{tabular}{|c|c|c|c|c|}
\hline \multirow{3}{*}{ Tratamentos } & \multicolumn{4}{|c|}{ Atratividade } \\
\hline & \multicolumn{4}{|c|}{ Minutos } \\
\hline & 5 & 15 & 30 & 60 \\
\hline Mucuna-preta & $0,88 \pm 0,40 b$ & $1,04 \pm 0,58 a b$ & $1,04 \pm 0,58 b$ & $1,04 \pm 0,58 b$ \\
\hline Feijão-guandu & $1,22 \pm 0,58 b$ & $1,11 \pm 0,63 a b$ & $0,98 \pm 0,40 b$ & $1,04 \pm 0,58 b$ \\
\hline Feijão-de-porco & $2,09 \pm 1,28 a$ & $1,97 \pm 0,87 a$ & $2,33 \pm 0,56 a$ & $2,13 \pm 0,86 a$ \\
\hline Nabo-forrageiro & $0,98 \pm 0,40 b$ & $1,32 \pm 0,51 a b$ & $1,29 \pm 0,60 b$ & $1,39 \pm 0,80 a b$ \\
\hline Crotalaria juncea & $0,91 \pm 0,25 b$ & $0,81 \pm 0,20 b$ & $0,81 \pm 0,20 b$ & $1,02 \pm 0,24 b$ \\
\hline Milheto & $0,71 \pm 0,10 b$ & $0,91 \pm 0,24 b$ & $0,91 \pm 0,25 b$ & $0,91 \pm 0,24 b$ \\
\hline F (trat.) & $7,44^{* *}$ & $3,87^{*}$ & $9,73^{* *}$ & 4,32 ** \\
\hline C.V (\%) & 36,14 & 39,76 & 32,91 & 39,2 \\
\hline \multirow{2}{*}{ Tratamentos } & \multicolumn{4}{|c|}{ Horas } \\
\hline & 2 & 6 & 12 & 24 \\
\hline Mucuna-preta & $1,04 \pm 0,58 b$ & $1,15 \pm 0,54 b c$ & $1,06 \pm 0,49 b$ & $1,09 \pm 0,37 b c$ \\
\hline Feijão-guandu & $1,02 \pm 0,24 b$ & $0,91 \pm 0,24 c$ & $0,70 \pm 0,11 b$ & $0,88 \pm 0,40 b c$ \\
\hline Feijão-de-porco & $2,33 \pm 0,55 a$ & $2,15 \pm 0,58 a$ & $2,03 \pm 0,86 a$ & $2,08 \pm 1,24 a$ \\
\hline Nabo-forrageiro & $1,45 \pm 0,84 b$ & $1,73 \pm 0,51 a b$ & $2,52 \pm 0,83 a$ & $1,85 \pm 1,47 a b$ \\
\hline Crotalaria juncea & $0,91 \pm 0,24 b$ & $0,91 \pm 0,24 c$ & $0,70 \pm 0,11 b$ & $0,71 \pm 0,31 c$ \\
\hline Milheto & $0,91 \pm 0,24 b$ & $0,91 \pm 0,24 c$ & $0,70 \pm 0,11 b$ & $1,02 \pm 0,24 b c$ \\
\hline F (trat.) & $8,34^{* *}$ & $12,13^{* *}$ & $28,78^{* *}$ & $6,45^{* *}$ \\
\hline C.V (\%) & 33,51 & 26,05 & 25,67 & 38,71 \\
\hline
\end{tabular}

Médias na coluna seguidas da mesma letra não diferem estatisticamente entre si, de acordo com o teste de Tukey ao nível de $5 \%$ de probabilidade [para análise, os dados foram transformados em $(x+0,5)^{1 / 2}$ ]; * significativo a $5 \%$ de probabilidade; * ${ }^{*}$ significativo a $1 \%$ de probabilidade; NS: não significativo; EPM: Erro Padrão da Média. C.V: Coeficiente de Variação. 
Ao observar os valores referentes à massa seca consumida em teste com chance de escolha, visualiza-se que a espécie milheto foi a menos consumida por $S$. eridania, enquanto a nabo-forrageiro foi a mais consumida (Fig. 1).

Comparando a atratividade das lagartas pelos diferentes hospedeiros e a massa consumida, nota-se que houve uma relação direta, pela qual a espécie menos atrativa gerou um efeito de deterrência na alimentação da praga. A menor alimentação neste hospedeiro pode ser atribuída à existência de uma cutícula mais espessa em relação aos demais, consequentemente reduzindo a alimentaçáo das lagartas. O fator espessura atua principalmente em insetos de pequeno porte e sobre os primeiros ínstares (LARA, 1991). Outro fator poderia ser a

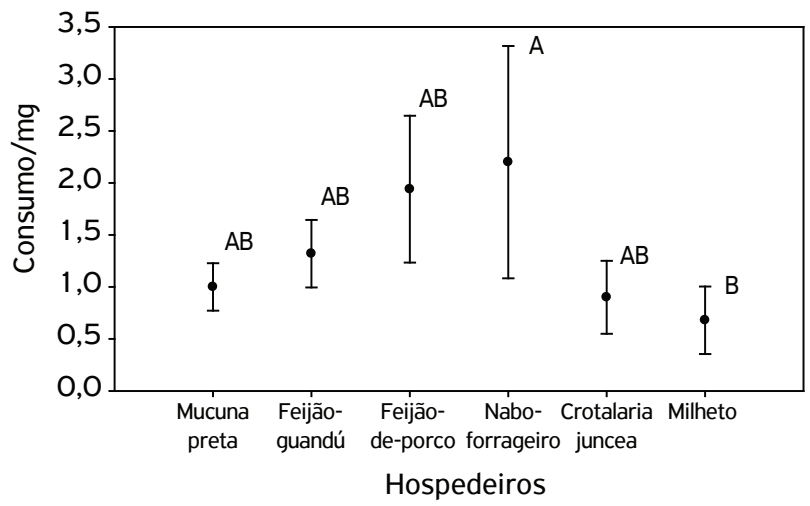

Figura 1. Médias ( \pm EPM) da massa seca consumida (mg) por Spodoptera eridania em diferentes hospedeiros. Letras diferentes sobre as barras representam médias estatisticamente diferentes pelo teste de Tukey, sendo $\mathrm{P}<0,05 ; \mathrm{F}$ tratamentos = 2,86; e C.V $(\%)=33,20$. presença de algum aleloquímico que iniba a alimentação dos insetos neste hospedeiro (VENDrAmim; Guzzo, 2009).

Quanto aos dados apresentados na Tabela 2 referentes aos parâmetros biológicos da praga alimentada nos diferentes hospedeiros, notam-se diferenças significativas nas avaliaçóes realizadas, exceto para o período pupal e para a razão sexual.

As lagartas criadas com folhas de feijão-de-porco tiveram maior duração média do período larval do que aquelas criadas com folhas de nabo-forrageiro e C. juncea. A diferença média foi de 7,09 dias a mais no feijão-de-porco em relaçáo ao nabo-forrageiro, e 7,16 dias a mais no feijão-de-porco em relação à $C$. juncea. Os insetos alimentados com milheto não completaram a fase larval.

A duração do estádio larval de $S$. eridania nos diferentes hospedeiros (Tabela 2) está próxima aos achados de outros autores em outros hospedeiros. PArra et al. (1977), a $27^{\circ} \mathrm{C}$ e UR de $80 \%$, observaram duração de 16,6 dias em algodoeiro e 14,3 dias em soja. Já SANTOs et al. (2005) observaram valores de 15,9 dias para algodoeiro, 15,7 dias para corda-de-viola e 18,3 dias para soja. Lagartas de S. eridania alimentadas com folhas de batata-doce e bracatinga apresentaram duração do estágio larval de 18,1 e 32,0 dias, respectivamente (Mattana; Foerster, 1988).

Observando os diferentes hospedeiros com relação ao peso larval do inseto, visualizamos que o nabo-forrageiro proporcionou os melhores valores para a espécie. Quando as larvas se alimentaram de milheto, feijão-de-porco e feijão-guandu, apresentaram os menores pesos larvais. Esta diferença se explica, possivelmente, pelo fato de o primeiro hospedeiro apresentar composição nutricional mais satisfatória para a

Tabela 2. Médias ( \pm EPM) da duração do período larval e pupal (dias), peso larval e pupal (mg), viabilidade larval e pupal (\%), razão sexual e longevidade de adultos (dias) de Spodoptera eridania em diferentes hospedeiros.

\begin{tabular}{|c|c|c|c|c|}
\hline \multirow{2}{*}{ Tratamentos } & \multicolumn{4}{|c|}{ Parâmetros avaliados ${ }^{1}$} \\
\hline & Período Larval & Peso Larval & Viabilidade Larval & Período Pupal \\
\hline Mucuna-preta & $21,50 \pm 0,50 b$ & $164,0 \pm 0,30 a b$ & $13,33 \pm 9,08 c$ & $3,00 \pm 0,10$ \\
\hline Feijão-guandu & $21,50 \pm 0,27 b$ & $115,0 \pm 0,10 c$ & $66,66 \pm 12,60 a b$ & $3,50 \pm 0,27$ \\
\hline Feijão-de-porco & $26,87 \pm 0,72 a$ & $96,0 \pm 0,30 c$ & $33,33 \pm 12,60 b c$ & $4,00 \pm 0,35$ \\
\hline Nabo-forrageiro & $19,78 \pm 0,19 c$ & $364,0 \pm 0,30 a$ & $86,66 \pm 9,08 a$ & $4,80 \pm 0,49$ \\
\hline Crotalaria juncea & $19,71 \pm 0,32 c$ & $231,0 \pm 0,20 b$ & $93,33 \pm 6,67 a$ & $4,40 \pm 0,42$ \\
\hline Milheto & - & $72,0 \pm 0,50 c$ & - & - \\
\hline $\mathrm{F}$ (trat.) & $74,46^{* *}$ & $20,45^{* *}$ & 11,26 ** & $2,45^{\text {ns }}$ \\
\hline C.V (\%) & 5,49 & 5,16 & 60,01 & 12,84 \\
\hline Tratamentos & Peso Pupal & Viabilidade Pupal & Razão Sexual & Longevidade de Adultos \\
\hline Mucuna-preta & $132,0 \pm 0,40 b$ & $62,88 \pm 15,76 a b$ & $0,62 \pm 0,17$ & $10,01 \pm 0,41 \mathrm{a}$ \\
\hline Feijão-guandu & $182,0 \pm 0,60 b$ & $54,54 \pm 12,25 a b$ & $0,64 \pm 0,15$ & $9,75 \pm 0,32 a b$ \\
\hline Feijão-de-porco & $203,0 \pm 0,60 b$ & $25,00 \pm 13,10 b$ & $0,57 \pm 0,26$ & $6,13 \pm 0,21 b$ \\
\hline Nabo-forrageiro & $246,0 \pm 0,90 a$ & $76,92 \pm 12,16 a$ & $0,69 \pm 0,13$ & $8,42 \pm 0,29 a b$ \\
\hline Crotalaria juncea & $260,0 \pm 0,20 a$ & $53,33 \pm 13,33 a b$ & $0,42 \pm 0,14$ & $10,89 \pm 0,45 a$ \\
\hline Milheto & - & - & - & - \\
\hline $\mathrm{F}$ (trat.) & $19,71^{\text {** }}$ & $12,7^{*}$ & $1,23^{\text {ns }}$ & $8,47^{*}$ \\
\hline C.V (\%) & 1,9 & 43,94 & 25,15 & 26,32 \\
\hline
\end{tabular}

Médias seguidas da mesma letra não diferem estatisticamente entre si, de acordo com o teste de Tukey ao nível de $5 \%$ de significância. Para análise, os dados foram transformados em $\left.(x+0,5)^{1 / 2}\right)$; ${ }^{*}$ significativo a $5 \%$ de probabilidade; * significativo a $1 \%$ de probabilidade; NS: não significativo; EPM: Erro Padrão da Média; C.V: Coeficiente de Variação. 
fase larval e melhor adequaçáo da espécie a essa planta, o que mostra a influência do hospedeiro no ciclo de desenvolvimento da praga.

Os hospedeiros demonstraram influenciar a sobrevivência da fase larval do inseto, com destaque para as lagartas alimentadas com folhas de $C$. juncea e nabo-forrageiro, cuja sobrevivência foi de 86,66 e 93,33\%, respectivamente (Tabela 2). Mattana; Foerster (1988) obtiveram 100\% de sobrevivência larval em batata-doce. SANTos et al. (2005) obtiveram $83,52 \%$ em algodoeiro, $98 \%$ em corda-de-viola e $80 \%$ em soja.

Os hospedeiros náo influenciaram o período pupal, porém, pupas oriundas de lagartas criadas com $C$. juncea e nabo-forrageiro apresentaram maiores pesos em comparação com aquelas que foram criadas com mucuna-preta, feijão-guandu e feijão-de-porco. A sobrevivência da pupa (Tabela 2) foi menor para as lagartas alimentadas com feijão-de-porco em relação às alimentadas com nabo-forrageiro (Tabela 2).

Observando os parâmetros biológicos referentes à fase pupal, estes diferiram dos documentados na bibliografia para outros hospedeiros. Lagartas de S. eridania alimentadas com bracatinga, a $30^{\circ} \mathrm{C}$, permaneceram 7,6 dias na fase de pupa (Foerster; Dionisio, 1989). Santos et al. (2005) observaram que os insetos permaneceram nesta fase por 8,4 dias com algodoeiro, 8,8 dias com corda-de-viola e 8,9 dias com soja. Para o peso pupal, resultados semelhantes foram obtidos quando comparados com lagartas criadas em folhas de algodoeiro, com 0,23 e 0,28 g; em soja, com 0,17 e $0,19 \mathrm{~g}$ (Santos et al., 2005); em batata-doce, com 0,2 e $0,3 \mathrm{~g}$, para machos e fêmeas, respectivamente, e bracatinga, com 0,2 g para ambos os sexos (Mattana; FoERSTER, 1988).

Em relação à longevidade dos adultos, foram constatadas diferenças significativas. Insetos provenientes da dieta de folhas de mucuna-preta e $C$. juncea viveram em média 3,88 e 4,76 dias a mais quando comparados às lagartas alimentadas com folhas de feijáo-de-porco (Tabela 2).

Esse resultado aproxima-se dos obtidos por outros autores em diferentes hospedeiros. PARRA et al. (1977) encontraram que machos criados em folhas de soja apresentaram longevidade de 3,4 dias menos em relação aos criados em algodoeiro. Mattana; Foerster (1988) observaram que adultos oriundos de folhas de batata-doce tiveram longevidade menor do que aqueles provenientes da bracatinga. Santos et al. (2005) observaram que adultos criados com folhas de algodoeiro tiveram mais longevidade quando comparados com corda-de-viola e soja, respectivamente.

A duração média do ciclo de vida total (ovo até morte do adulto) variou em função do hospedeiro oferecido como

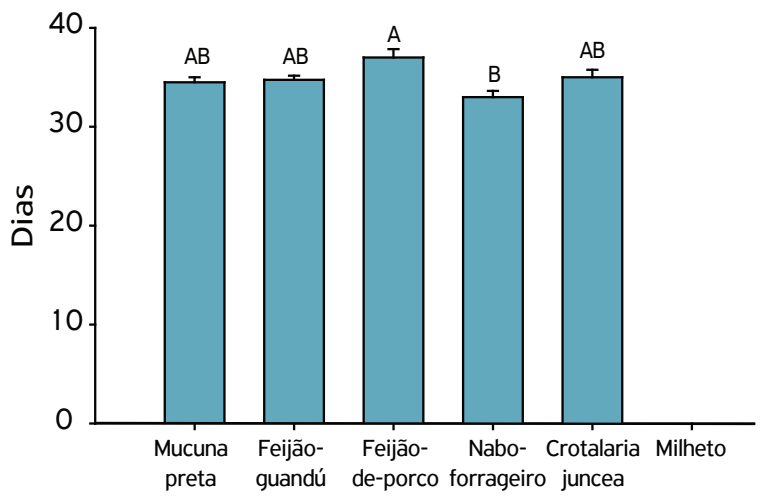

Figura 2. Médias ( \pm EPM) da duração total do ciclo de vida (dias) de Spodoptera eridania em diferentes hospedeiros. As letras diferentes sobre as barras representam médias estatisticamente diferentes de acordo com o teste de Tukey, sendo $p>0,05 ; F$ tratamentos = 3,46; e CV $(\%)=5,53$.

alimento. Houve redução média de 4,0 dias para as lagartas alimentadas com folhas de feijão-de-porco em comparação com o nabo-forrageiro (Fig. 2). Nesses hospedeiros, a duraçáo do ciclo foi próxima àquela encontrada por PARRA et al. (1977), ou seja, 34,3 dias em soja, e SAntos et al. (2005), que encontraram 28,5 dias em algodoeiro e 32 dias em corda-de-viola e soja, respectivamente.

Essa diferença nos parâmetros biológicos referente à fase pupal está provavelmente relacionada à não-preferência das lagartas por alguns desses hospedeiros, à ingestão de substâncias presentes nas folhas que prejudicaram o seu desenvolvimento (antibiose), à impropriedade nutricional presente no hospedeiro ou à combinação de tais fatores (SAntos; BorçA JUNIOR, 2001).

\section{CONCLUSÃO}

As plantas de feijão-de-porco e nabo-forrageiro apresentaram maior atratividade e foram as mais consumidas pelas lagartas de S. eridania. O período larval foi menor nas lagartas alimentadas com mucuna-preta do que com feijāo-guandu, feijấo-de-porco, nabo-forrageiro e $C$. juncea.

Lagartas alimentadas com folhas de nabo-forrageiro e $C$. juncea tiveram os maiores peso de pupa. Os melhores desenvolvimentos das lagartas foram obtidos nos hospedeiros feijão-guandu, nabo-forrageiro e $C$. juncea.

$\mathrm{O}$ hospedeiro milheto influenciou negativamente os parâmetros biológicos das lagartas, não tendo se mostrado como um hospedeiro viável, visto que a mortalidade larval foi de $100 \%$. 


\section{REFERÊNCIAS}

BUTT B.A.; CANTU, E. Sex determination of lepidopterous pupae. Washington: United States Department of Agriculture (USDA), Agricultural Research Service. 1962.7p.

DIAS, N.S.; MICHELETTI, S.B.; TOURINHO, L.L.; RODRIGUES, V.M. Primeiro registro de ocorrência de Spodoptera spp. (Lepidoptera: noctuidae) atacando crotalária no estado de Alagoas, Brasil. Caatinga, v.22, n.1, p.1-3, 2009.

FERNANDEZ, M.G. Distribuição espacial e amostragem sequencial dos principais noctuídeos do algodoeiro (Gossypium hirsutum L.). 2002. 140 f. Tese (Doutorado) - Universidade Estadual Paulista, Jaboticabal, 2002.

FOERSTER, L.A.; DIONÍSIO, A.L.M. Necessidades térmicas de Spodoptera eridania (Cramer, 1782) (Lepidoptera: Noctuidae) em Bracatinga (Mimosa scabrella Bentham) (Leguminosae). Anais da Sociedade Entomológica do Brasil, v.18, n. 1, p.145-154, 1989.

GALLO, D.; SILVEIRA NETO, S.; CARVALHO, R.P.L.; BAPTISTA, G.C.; BERTI FILHO, E.; PARRA, J.R.P.; ZUCCHI, R.A.; ALVES, S.B.; VENDRAMIN, J.D.; MARCHINI, L.C.; LOPES, J.R.S.; OMOTO, C. Entomologia Agrícola. Piracicaba: Fealq. 2002. 920p.

LARA, F.M. Princípios de resistência de plantas aos insetos. São Paulo: Ícone. 1991. 336p.

MATTANA, A.L.; FOERSTER, L.A. Ciclo de vida de Spodoptera eridania (Cramer, 1782) (Lepidoptera: Noctuidae) em um novo hospedeiro, Bracatinga (Mimosa scabrella Bentham) (Leguminosae). Anais da Sociedade Entomológica do Brasil, v.17, n.1, p.173-183, 1988.

PANIZZI, A.R.; PARRA, J.R.P. Introdução à bioecologia e nutrição de insetos como base para o manejo integrado de pragas. In: PANIZZI, A.R.; PARRA, J.R.P. Bioecologia e nutrição de insetos: base para o manejo integrado de pragas. Brasília: EMBRAPA, 2009. p.21-36.

PARRA, J.R.P.; PRECETTI, A.A.C.M.; KARSTEN JUNIOR, P. Aspectos biológicos de Spodoptera eridania (Cramer, 1782) (Lepidoptera: Noctuidae) em soja e algodão. Anais da Sociedade Entomológica do Brasil, v.6, n.1, p.147-155, 1977.

PEREIRA, J.M.; SEII, A.H.; OLIVEIRA, M.F.; BRUSTOLIN, C.; FERNANDES, O.M. Mortalidade de lagartas de Spodoptera eridania (Cramer) pela utilização de Bacillus thuringiensis (Berliner). Pesquisa Agropecuária Tropical, v.39, n.2, p.140-143, 2009.

PITRE, H.N.; HOGG, D.B. Development of the fall armyworm on cotton, soybean and corn. Journal Georgia Entomological Society, v.18, n.2, p.182-187, 1983.

SANTOS, K.B. Caracterização dos danos de Spodoptera eridania (Cramer) e Spodoptera cosmioides (Walker) (Lepidoptera: Noctuidae) a estruturas de algodoeiro. Neotropical Entomology, v.39, n.4, p.626-631, 2010

SANTOS, K.B.; NEVES, P.M.O.J.; MENEGUIM, A.M. Biologia de Spodoptera eridania (Cramer) (Lepidoptera: Noctuidae) em diferentes hospedeiros. Neotropical Entomology, v.34, n.6, p.903-910, 2005.

SANTOS, T.M.; BOIÇA JUNIOR, A.L. Resistência de genótipos de algodoeiro (Gossypium hirsutum L.) a Alabama argillacea (Hübner) (Lepidoptera: Noctuidae). Neotropical Entomology, v.30, n.2, p.297-303, 2001

SAVOIE, K.L. Selective feeding by species of Spodoptera (Lepidoptera: Noctuidae) in a bean field with minimum tillage. Turrialba, v.38, n.1, p.67-70, 1988.

SOSA-GÓMEZ, D.R. Pragas da soja e seu controle. In: ARANTES, N.P.; SOUZA, P.I.M. (ed.). Cultura da soja nos cerrados. Piracicaba: Potafos. 1993. 535p.

SOUZA, B.H.S.; BOTTEGA, D.B.; SILVA, A.G.; BOIÇA JUNIOR, A.L. Feeding non-preference by Spodoptera frugiperda and Spodoptera eridania on tomato genotypes. Ceres, v.60, n.1, p.21-29, 2013.

SOUZA, B.H.S.; BOIÇA JUNIOR, A.L.; JANINI, J.C.; SILVA, A.G.; RODRIGUES, N.E.L. Feeding of Spodoptera eridania (Lepidoptera: Noctuidae) on soybean genotypes. Revista Colombiana de Entomologia, v.38, n.2, p.215-223, 2012.

VENDRAMIM, J.D.; GUZZO, E.C. Resistência de plantas e a bioecologia e nutrição de insetos. In: PANIZZI, A.R.; PARRA, J.R.P. Bioecologia e nutrição de insetos: base para o manejo integrado de pragas. Brasília: EMBRAPA. 2009. p. 1055-1106. 